\title{
Volatility of Some Selected Currencies Against the Naira Using Generalized Autoregressive Score Models
}

\section{Oluwagbenga Tobi Babatunde*, Henrietta Ebele Oranye, Cynthia Ndidiamaka Nwafor}

Department of Statistics, Faculty of Physical Sciences, University of Nigeria, Nsukka, Nigeria

\section{Email address:}

babatundegbenge03@gmail.com (O. T. Babatunde), Henrietta.oranye@unn.edu.ng (H. E. Oranye),

ndidiamaka.umegwuagu@unn.edu.ng (C. N. Nwafor)

${ }^{*}$ Corresponding author

\section{To cite this article:}

Oluwagbenga Tobi Babatunde, Henrietta Ebele Oranye, Cynthia Ndidiamaka Nwafor. Volatility of Some Selected Currencies Against the Naira Using Generalized Autoregressive Score Models. International Journal of Statistical Distributions and Applications.

Vol. 6, No. 3, 2020, pp. 42-46. doi: 10.11648/j.ijsd.20200603.11

Received: July 20, 2020; Accepted: July 30, 2020; Published: August 27, 2020

\begin{abstract}
The role exchange rate plays in international trade and bilateral agreement between countries cannot be overemphasize. Fluctuations in exchange rate has direct impact on the economy of any country especially a country like Nigeria which depends largely on import goods. So, there is need to identify appropriate model that can adequately describe the dynamics of the exchange rate volatilities. This article investigated the volatility of exchange rates in Nigeria by selecting the U.S dollars, Pound Sterling and Euro against the Naira using daily data over the period of January 02, 2002 to August 31, 2018. The GAS model with its variants was applied to study the volatility of the exchange rates assuming three different probability distributions for the innovations of the models namely; Normal distribution (N), Student-t distribution (T) and Skewed-Student-t distribution (SKT). The AIC and SBIC estimates obtained were used to access fitness performance. The GAS model and its variants' forecasting ability were access using several forecast measures. Using the estimates of the AIC and SBIC, GAS-T, EGAS-T and EGAS-STK were selected for US dollars/Naira, Pound sterling/Naira and Euro/Naira exchange rates respectively as the best fitted models. Based on the estimates of MAE and RMSE, GAS-T, EGAS-T and EGAS-SKT were selected for forecasting the volatility of US dollars/Naira, Pound sterling/Naira and Euro/Naira exchange rates respectively.
\end{abstract}

Keywords: Volatility, Generalized Autoregressive Score, Exchange Rates, Innovations

\section{Introduction}

Managing the risks due to volatility is an essential factor in understanding the currency market worldwide [1]. The ARCH model of Engle has been extensively used in literature to study the volatility of the exchange rate of one currency against another [2]. The ARCH model was initially developed as a simple quadratic function of the lagged values of the return series. Bollerslev suggested a solution for the shortcomings of the ARCH model by generalizing the ARCH model as GARCH $(p, q)$ model [3]. The introduction of the GARCH $(p, q)$ model has led to the development of several other models due to its inability to capture asymmetry effect. Many other variants of the model have been proposed to capture asymmetry (see [4-6]) and nonlinearity (see [7]). Yaya et al. noted that the classical GARCH model of Bollerslev and the asymmetric models developed from it were unable to detect jumps or unusual changes in a return series thereby under-estimating the value of the returns $[3,8]$. Recently, volatility models that capture jumps and outliers have been proposed and these form the class Generalized Autoregressive Score (GAS) model. Harvey and Chakravarty proposed the GAS model with Exponential GAS (EGAS) and Asymmetric EGAS (AEGAS) as its variants $[9,10]$. Recent literatures on the GAS models are found in [11-17], 'in press' [18]. Several studies exist in literature on the theoretical framework of the GAS model. Babatunde et al. investigated the specification and misspecification of the GAS model with its variants assuming different probability distributions for the innovations of the models $[18,19]$. On the application of the GAS models with its variants, Calvori et al. proposed and applied a novel GAS model to the daily volume shares of the New York Stock Exchange and confirms its ability to capture the dynamics of the daily volume shares [13]. 
Exchange rate plays a vital role in international trade and bilateral agreement between countries and as such this paper tries to explore the GAS variants in studying the dynamics of the volatility of US Dollars, Pound Sterling and Euro against the naira and also assess the ability of the models to forecast future volatilities. To the best of our knowledge, the new GAS variants have not been applied to the US Dollars/ Naira, Pound Sterling/Naira and Euro/Naira exchange rates.

\section{Methodology}

\subsection{GAS Variants}

Given a return series $y_{t}=\varepsilon_{t}$, the $\operatorname{GARCH}(1,1)$ model is specified as:

$$
\sigma_{t}^{2}=\omega+\alpha_{1} \varepsilon_{t-1}^{2}+\beta_{1} \sigma_{t-1}^{2}
$$

Given that $\varepsilon_{t}=z_{t} \sigma_{t}$, (1) becomes

$$
\sigma_{t}^{2}=\omega+\alpha_{1}\left(z_{t-1}^{2}-1\right) \sigma_{t-1}^{2}+\left(\alpha_{1}+\beta_{1}\right) \sigma_{t-1}^{2}
$$

The specification of the GAS $(1,1)$ model of Harvey and Chakravarty [9] is given as:

$$
\sigma_{t}^{2}=\omega+\alpha_{1} \mu_{t-1} \sigma_{t-1}^{2}+\varphi_{1} \sigma_{t-1}^{2}
$$

Where $\mu_{t}$ is the innovation of the GAS model, which assumes three different distributions as mentioned earlier. The GAS $(1,1)$ model of Harvey and Chakravarty combined with the assumed probability distribution of the innovations was expressed in Babatunde et al. [9, 'in press' 18] as follows:

GAS-Normal:

$$
\sigma_{t}^{2}=w+\alpha_{1}\left(z_{t-1}^{2}-1\right) \sigma_{t-1}^{2}+\varphi_{1} \sigma_{t-1}^{2}
$$

GAS-Student-t:

$$
\sigma_{t}^{2}=w+\alpha_{1}\left(\frac{(v+1) z_{t-1}^{2}}{v-2+z_{t-1}^{2}}-1\right) \sigma_{t-1}^{2}+\varphi_{1} \sigma_{t-1}^{2}
$$

$$
\sigma_{t}^{2}=w+\alpha_{1}\left(\frac{(v+1) z_{t-1} z_{t-1}^{*}}{(v-2)+g_{t-1} \xi^{I_{t-1}}}-1\right) \sigma_{t-1}^{2}+\varphi_{1} \sigma_{t-1}^{2}
$$

Where, $z_{t}^{*}=\mathrm{s} z_{t}+\mathrm{m}$

$$
\begin{aligned}
& I_{t}=\operatorname{sgn}\left(z_{t}^{*}\right)=\mathrm{I}\left(z_{t}^{*} \geq 0\right)-I\left(z_{t}^{*}<0\right) ; g_{t}=1+\frac{z_{t}^{* 2}}{(v-2) \xi^{2 I_{t}}} \\
& \mathrm{M}=\frac{\Gamma\left(\frac{v-1}{2}\right) \sqrt{v-2}}{\sqrt{\pi} \Gamma\left(\frac{v}{2}\right)}\left(\xi-\frac{1}{\xi}\right) ; \mathrm{S}=\sqrt{\left(\xi^{2}+\frac{1}{\xi^{2}}-1\right)-m^{2}}
\end{aligned}
$$

Harvey and Chakravarty also considered an Exponential GARCH (EGARCH)-type version of the GAS model called EGAS [9]. The EGAS $(1,1)$ model is given as:

$$
\log \sigma_{t}^{2}=\omega+\alpha_{1} \mu_{t-1}+\psi_{1} \log \sigma_{t-1}^{2}
$$

Introducing leverage effect to the EGAS model using the sign of the observation yields the AEGAS model. The AEGAS $(1,1)$ model is given as:

$$
\log \sigma_{t}^{2}=\omega+\alpha_{1} \mu_{t-1}+\gamma_{1} l_{t-1}+\psi_{1} \log \sigma_{t-1}^{2}
$$

Where,

$l_{t-1}=\operatorname{sgn}\left(-z_{t}\right)\left(\mu_{t}+1\right)$ for the Normal and Student-t distributions,

$\gamma_{1}$ is the asymmetric parameter. and $l_{t-1}=\operatorname{sgn}\left(-z_{t}^{*}\right)\left(\mu_{t}+1\right)$ for the Skewed Student-t distribution

The EGAS and AEGAS combined with a Normal (N), Student-t (T) and Skewed-Student (SKT) distribution were expressed in Babatunde et al. 'in press' [18] as follows:

EGAS-Normal:

$$
\log \sigma_{t}^{2}=w+\alpha_{1}\left(z_{t-1}^{2}-1\right)+\varphi_{1} \log \sigma_{t-1}^{2}
$$

EGAS-Student-t:

$$
\log \sigma_{t}^{2}=w+\alpha_{1}\left(\frac{(v+1) z_{t-1}^{2}}{v-2+z_{t-1}^{2}}-1\right)+\varphi_{1} \log \sigma_{t-1}^{2}
$$

EGAS-Skewed-Student-t:

GAS-Skewed-Student-t:

$$
\log \sigma_{t}^{2}=w+\alpha_{1}\left(\frac{(v+1) z_{t-1} z_{t-1}^{*}}{(v-2)+g_{t-1} \xi^{I_{t-1}}}-1\right)+\varphi_{1} \log \sigma_{t-1}^{2}
$$

AEGAS-Normal:

$$
\log \sigma_{t}^{2}=w+\alpha_{1}\left(z_{t-1}^{2}-1\right)+\gamma_{1} l_{t-1}+\varphi_{1} \log \sigma_{t-1}^{2}
$$

AEGAS-Student-t:

$$
\log \sigma_{t}^{2}=w+\alpha_{1}\left(\frac{(v+1) z_{t-1}^{2}}{v-2+z_{t-1}^{2}}-1\right)+\gamma_{1} l_{t-1}+\varphi_{1} \log \sigma_{t-1}^{2}
$$

AEGAS-Skewed-Student-t: 


$$
\log \sigma_{t}^{2}=w+\alpha_{1}\left(\frac{(v+1) z_{t-1} z_{t-1}^{*}}{(v-2)+g_{t-1} \xi^{I_{t-1}}}-1\right)+\gamma_{1} l_{t-1}+\varphi_{1} \log \sigma_{t-1}^{2}
$$

\subsection{Model Fitness and Forecast Performance}

The fitness of the GAS variants under the three assumed probability distributions will be assessed using Akaike information criteria (AIC) and Schwarz Bayesian information criteria (SBIC). For the three different exchange rates against naira, the model with the least information criteria will be adjudged as the best.

The forecasting performance of the GAS model and its variants will be evaluated using Mean Error (ME), Mean Absolute Error (MAE) and Root Mean Square Error (RMSE).

\section{Data and Empirical Analysis}

Daily exchange rates of US dollar, Pound Sterling and Euro against the naira were obtained from the website of the Central Bank of Nigeria (https://www.cbn.gov.ng). The data ranges from January 2, 2002 to August 31, 2018 making a total of 4061 daily observations. The exchange rates of the three currencies against the Naira are plotted in figure 1 while the plots of the log returns are presented in figure 2. A steady increase in the exchange rates of the three currencies against the naira can be observed in figure 1 . However, figure 2 shows stability in the returns of the exchange rates of the three currencies against the naira with few spikes at different point in time.

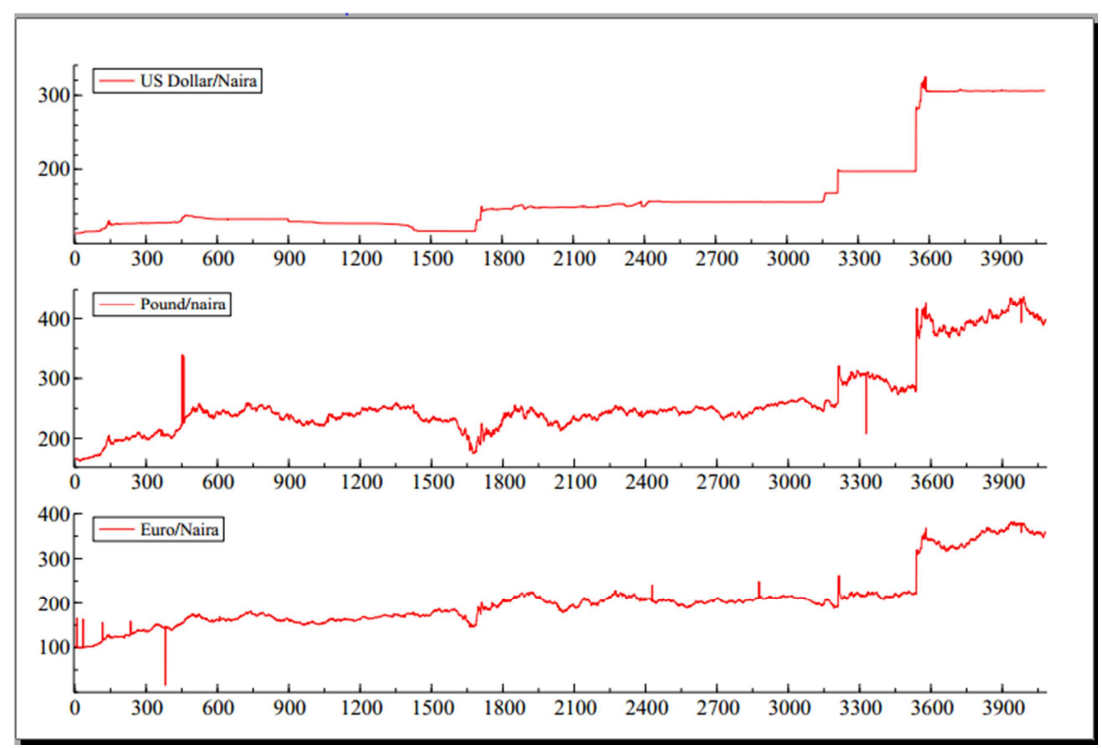

Figure 1. Plots of the exchange rates.
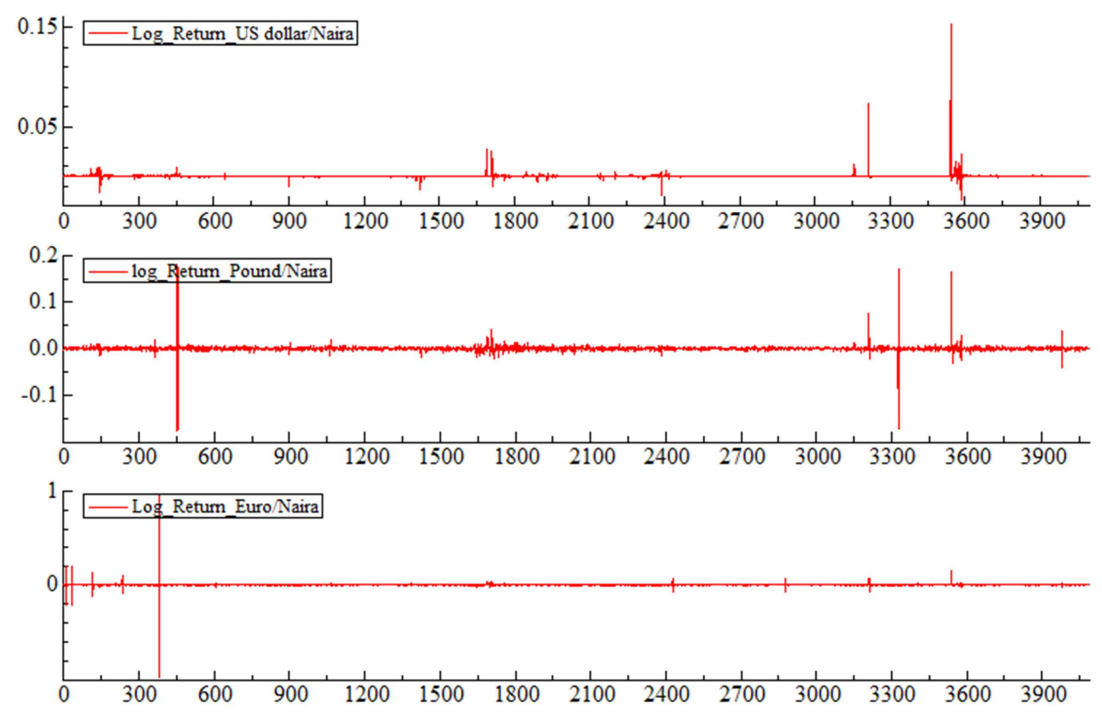

Figure 2. Plots of the log returns. 
Table 1 presents the results obtained from fitting the GAS variants to the US Dollars/Naira exchange rate data. The fitness of the models was assessed using the estimates of AIC and SBIC obtained from the models. Based on the estimates of both AIC and SBIC, the GAS-T model performs better when compare to the other GAS variants considered having the least AIC and SBIC estimates of-10.9145 and-10.9047 respectively. From the results presented in table 1, GAS-T model outperforms the other GAS variants in terms of ability to forecast future volatilities of the US Dollars/Naira exchange rate based on ME, MAE and RSME estimates obtained.

Table 1. Volatility models for US dollar/Naira exchange rate.

\begin{tabular}{|c|c|c|c|c|c|c|c|c|c|}
\hline & GAS & & & EGAS & & & AEGAS & & \\
\hline & $\mathbf{N}$ & $\mathbf{T}$ & SKT & $\mathbf{N}$ & $\mathbf{T}$ & SKT & $\mathbf{N}$ & $\mathbf{T}$ & SKT \\
\hline AIC & -8.4349 & -10.9145 & -8.8546 & -9.8460 & -9.0521 & -5.7821 & -6.2631 & -10.4062 & -1.2900 \\
\hline $\begin{array}{l}\text { SBIC } \\
\text { Forecast Measure }\end{array}$ & -8.4271 & -10.9047 & -8.8429 & -9.8382 & -9.0423 & -5.7704 & -6.2534 & -10.3944 & -1.2763 \\
\hline $\mathrm{ME}$ & $3.65 \mathrm{E}-3$ & $2.50 \mathrm{E}-5$ & $3.59 \mathrm{E}-3$ & $8.87 \mathrm{E}-5$ & $6.44 \mathrm{E}-4$ & $2.79 \mathrm{E}-2$ & $2.12 \mathrm{E}-3$ & $5.63 \mathrm{E}-4$ & $2.34 \mathrm{E}-1$ \\
\hline MAE & $3.73 \mathrm{E}-3$ & $6.97 \mathrm{E}-4$ & $3.67 \mathrm{E}-3$ & $7.99 \mathrm{E}-4$ & $7.82 \mathrm{E}-4$ & $2.82 \mathrm{E}-2$ & $2.73 \mathrm{E}-3$ & $7.06 \mathrm{E}-4$ & $2.34 \mathrm{E}-1$ \\
\hline RMSE & $6.66 \mathrm{E}-3$ & $5.56 \mathrm{E}-3$ & $6.62 \mathrm{E}-3$ & $5.57 \mathrm{E}-3$ & $5.60 \mathrm{E}-3$ & $2.84 \mathrm{E}-2$ & $5.95 \mathrm{E}-3$ & $5.59 \mathrm{E}-3$ & $2.34 \mathrm{E}-1$ \\
\hline
\end{tabular}

Note: Best fitted in bold.

Table 2 presents the results obtained from fitting the GAS variants to the Pound Sterling/Naira exchange rate data. The fitness of the models was assessed using the estimates of AIC and SBIC obtained from the models. Based on the estimates of both AIC and SBIC, the EGAS-T model performs better when compare to the other GAS variants considered having the least AIC and SBIC estimates of-9.017 and-9.0094 respectively. From the results presented in table 2, EGAS-T model outperforms the other GAS variants in terms of ability to forecast future volatilities of the Pound Sterling/Naira exchange rate based on ME, MAE and RSME estimates obtained.

Table 2. Volatility models for Pound Sterling/Naira exchange rate.

\begin{tabular}{|c|c|c|c|c|c|c|c|c|c|}
\hline & \multicolumn{3}{|l|}{ GAS } & \multicolumn{3}{|l|}{ EGAS } & \multicolumn{3}{|l|}{ AEGAS } \\
\hline & $\mathbf{N}$ & $\mathbf{T}$ & SKT & $\mathbf{N}$ & $\mathbf{T}$ & SKT & $\mathbf{N}$ & $\mathbf{T}$ & SKT \\
\hline AIC & -7.5650 & -9.0165 & -9.0160 & -7.4234 & -9.0173 & -9.0169 & -7.3518 & -9.0169 & -9.0164 \\
\hline $\begin{array}{l}\text { SBIC } \\
\text { Forecast Measure }\end{array}$ & -7.5587 & -9.0086 & -9.0065 & -7.4172 & -9.0094 & -9.0074 & -7.3439 & -9.0074 & -9.0054 \\
\hline $\mathrm{ME}$ & $7.39 \mathrm{E}-4$ & $-3.68 \mathrm{E}-4$ & $-3.77 \mathrm{E}-4$ & $-4.21 \mathrm{E}-4$ & $-5.68 \mathrm{E}-4$ & $-3.76 \mathrm{E}-4$ & $-3.82 \mathrm{E}-4$ & $-3.65 \mathrm{E}-4$ & $-3.72 \mathrm{E}-3$ \\
\hline MAE & $1.85 \mathrm{E}-3$ & $1.76 \mathrm{E}-3$ & $1.76 \mathrm{E}-3$ & $1.77 \mathrm{E}-3$ & $1.72 \mathrm{E}-3$ & $1.76 \mathrm{E}-3$ & $1.76 \mathrm{E} 3$ & $1.76 \mathrm{E}-3$ & $1.76 \mathrm{E}-3$ \\
\hline RMSE & $2.37 \mathrm{E}-3$ & $2.28 \mathrm{E}-3$ & $2.29 \mathrm{E}-3$ & $2.29 \mathrm{E}-3$ & $2.24 \mathrm{E}-3$ & $2.29 \mathrm{E}-3$ & $2.29 \mathrm{E}-3$ & $2.28 \mathrm{E}-3$ & $2.28 \mathrm{E}-3$ \\
\hline
\end{tabular}

Note: Best fitted in bold.

Table 3 presents the results obtained from fitting the GAS variants to the Euro/Naira exchange rate data. The fitness of the models was assessed using the estimates of AIC and SBIC obtained from the models. Based on the estimates of both AIC and SBIC, the EGAS-SKT model performs better when compare to the other GAS variants considered having the least AIC and SBIC estimates of-8.7461 and-8.7344 respectively. From the results presented in table 3, EGASSKT model outperforms the other GAS variants in terms of ability to forecast future volatilities of the Euro/Naira exchange rate based on ME, MAE and RSME estimates obtained.

Table 3. Volatility models for Euro/Naira exchange rate.

\begin{tabular}{|c|c|c|c|c|c|c|c|c|c|}
\hline & \multicolumn{3}{|l|}{ GAS } & \multicolumn{3}{|l|}{ EGAS } & \multicolumn{3}{|l|}{ AEGAS } \\
\hline & $\mathbf{N}$ & $\mathbf{T}$ & SKT & $\mathbf{N}$ & $\mathbf{T}$ & SKT & $\mathbf{N}$ & $\mathbf{T}$ & SKT \\
\hline AIC & -1.6662 & -8.7441 & -8.7458 & -0.3601 & -5.8242 & -8.7461 & -1.6471 & -8.4927 & -8.7456 \\
\hline $\begin{array}{l}\text { SBIC } \\
\text { Forecas }\end{array}$ & -1.6584 & -8.7343 & -8.7341 & -0.3523 & -5.8144 & -8.7344 & -1.6373 & -8.4809 & -8.7312 \\
\hline $\mathrm{ME}$ & $-2.29 \mathrm{E}-3$ & $1.13 \mathrm{E}-4$ & $2.33 \mathrm{E}-4$ & $-5.95 \mathrm{E}-3$ & $2.23 \mathrm{E}-3$ & $-2.91 \mathrm{E}-4$ & $-2.85 \mathrm{E}-3$ & 7.69E-4 & $2.45 \mathrm{E}-4$ \\
\hline MAE & $3.47 \mathrm{E}-3$ & $2.36 \mathrm{E}-3$ & $2.35 \mathrm{E}-3$ & $6.68 \mathrm{E}-3$ & $3.05 \mathrm{E}-3$ & $-2.31 \mathrm{E}-3$ & $3.88 \mathrm{E}-3$ & $2.40 \mathrm{E}-3$ & $2.35 \mathrm{E}-3$ \\
\hline RMSE & $7.29 \mathrm{E}-3$ & $6.93 \mathrm{E}-3$ & $6.93 \mathrm{E}-3$ & $9.13 \mathrm{E}-3$ & 7.27E-3 & $6.83 \mathrm{E}-3$ & $7.49 \mathrm{E}-3$ & $6.97 \mathrm{E}-3$ & $6.93 \mathrm{E}-3$ \\
\hline
\end{tabular}

Note: Best fitted in bold.

\section{Conclusion}

The GAS model and its variants were fitted to the exchange rate of US dollar, Pound sterling and Euro against the Naira under the three assumed probability distributions for the innovations of the models. Based on information criteria (AIC and SBIC), GAS-T, EGAS-T and EGAS-SKT were selected as the best model for the US dollar/Naira, Pound/Naira and Euro/Naira exchange rates respectively. Based on the different forecast measures used (ME, MAE and RMSE), the GAS-T, EGAS-T and EGAS-SKT were also selected as the best models to forecast future volatilities of 
US dollar/Naira, Pound/Naira and Euro/Naira exchange rates respectively. By implication, GAS-T (assuming student-t for the innovations of the model) is preferred over the other GAS variants in studying the dynamics of the volatility of the US Dollars/Naira exchange rate. For the Pound Sterling/Naira exchange rate, The EGAS-T (assuming student-t for the innovations of the model) is preferred over the other GAS variants in studying the dynamics of the volatility of the Pound Sterling/Naira exchange rate. Also, for the Euro/Naira exchange rate, The EGAS-SKT (assuming skewed student-t for the innovations of the model) is preferred over the other GAS variants in studying the dynamics of the volatility of the Euro/Naira exchange rate.

\section{Acknowledgements}

The suggestions and comments of the anonymous reviewers are appreciated.

\section{References}

[1] Arachchi, A. K. (2018). Comparison of Symmetric and Asymmetric GARCH Mdels: Application of Exchange Rate Volatility. American Journal of Mathematics and Statistics, 8, 151-159.

[2] Engle, R. F. (1982). Autoregressive conditional heteroscedasticity with estimates of the variance of United Kingdom. Econometrica, 50: 987-1008.

[3] Bollerslev, T. (1986). Generalized autoregressive conditional heteroscedasticity. Journal of Econometrics 31: 307-27.

[4] Nelson, D. B. (1991). Conditional Heteroscedasticity in Asset Returns: A New Approach. Econometrica, 59, 347-370.

[5] Glosten, L. W., Jaganathan, R. and Runkle, D. E. (1993). “On the relation between the expected value and the volatility of the nominal excess return on stocks". Journal of Finance 48: $1779-1801$.

[6] Ding, Z., Granger, C. W. J. and Engle, R. F. (1993). "A long memory property of stock market returns and a new model". Journal of Empirical Finance, 1: 83-106.

[7] Gonzalez-Rivera, G. (1998). Smooth transition GARCH models. Studies in Nonlinear Dynamics and Econometrics 3, 61-78.
[8] Yaya, O. S., Bada, V. and Atoi, N. V. (2016). Volatility in the Nigerian Stock Market: Emperical Application of Beta-tGARCH Variants. CBN Journal of Applied Statistics, 7, 27-48.

[9] Harvey, A. and Chakravarty, T. (2008). Beta-t-(E)GARCH. Working paper series. University of Cambridge.

[10] Harvey, A. (2013). Dynamic Models for volatility and Heavy tails: with applications to financial and economic time series. Cambridge University Press, London.

[11] Blasques, F., Koopman, S. J. and Lucas, A. (2008). Stationarity and Ergodicity of Univariate GAS Process. Electronic Journal of Statistics. Vol. 8, pp. 1088-1112.

[12] Creal, D., Koopman, S. J., and Lucas, A. (2013). Generalized autoregressive score models with applications. Journal of Applied Econometrics, 28 (5): 777-795.

[13] Calvori, F., Cipollini, F. and Gallo, G. M. (2013). Go with the flow: A GAS Model for Predicting Intra-daily Volume Shares. Social Science Research Network. http://ssrn.com/abstract=2363483.

[14] Huang, Z., Wang, T. and Zhang, X. (2014). GAS model with realized measures of volatility. $\mathrm{http}: / /$ ssrn.com/abstract=2461831.

[15] Blasques, F., Koopman, S. J. and Lucas, A. (2014). Maximum Likelihood Estimation for GAS models. Tinbergen Institute Discussion Paper 14-029/III.

[16] Janus, P., Lucas, A. and Opschoor, A. (2014). New Heavy Models for FatTailed Returns and Realized Covariance Kernels. Tinbergen Institute Discussion Paper 14-073/IV.

[17] Bernadi, M. and Cantania, L. (2015). Switching-GAS copula models for systemic Risk Assessment. arxiv.org/abs/1504.03733vi.

[18] Babatunde, O. T., Yaya, O. S. and Oladugba, A., V. (2020). Investigating the Specification of the Distributional Assumption of the Innovations of Generalised Autoregressive Score Model with its Variants. International Journal of Applied Mathematics and Statistics, 59 (4).

[19] Babatunde, O. T., Yaya, O. S and Akinlana, D. M. (2019). Misspecification of Generalized Autoregressive Score Models: Monte Carlo Simulations and Applications. International Journal of Mathematics Trends and Technology, 65 (3). 